\title{
Dynamics of Ion Beam Stimulated Surface Mass Transport to Nanopores
}

\section{Citation}

Hoogerheide, David P., and Jene A. Golovchenko. 2007. Dynamics of Ion Beam Stimulated

Surface Mass Transport to Nanopores. MRS Proceedings 1020. doi:10.1557/proc-1020-gg02-01.

\section{Published Version}

doi:10.1557/PROC-1020-GG02-01

\section{Permanent link}

http://nrs.harvard.edu/urn-3:HUL.InstRepos:29405817

\section{Terms of Use}

This article was downloaded from Harvard University's DASH repository, and is made available under the terms and conditions applicable to Other Posted Material, as set forth at http:// nrs.harvard.edu/urn-3:HUL.InstRepos:dash.current.terms-of-use\#LAA

\section{Share Your Story}

The Harvard community has made this article openly available.

Please share how this access benefits you. Submit a story.

Accessibility 


\title{
Dynamics of Ion Beam Stimulated Surface Mass Transport to Nanopores
}

David P. Hoogerheide ${ }^{1}$, and Jene A. Golovchenko ${ }^{2}$

${ }^{1}$ Department of Physics, Harvard University, Cambridge, MA, 02138

${ }^{2}$ Department of Physics and School of Engineering and Applied Sciences, Harvard University, Cambridge, MA, 02138

\begin{abstract}
We explore the ion beam-induced dynamics of the formation of large features at the edges of nanopores in freestanding silicon nitride membranes. The shape and size of these "nanovolcanoes", together with the rate at which the nanopores open or close, are shown to be strongly influenced by sample temperature. Volcano formation and pore closing slow and stop at low temperatures and saturate at high temperatures. Nanopore volcano size and closing rates are dependent on initial pore size. We discuss both surface diffusion and viscous flow models in the context of these observed phenomena.
\end{abstract}

\section{INTRODUCTION}

The advent of solid state nanopores as single-molecule detectors [1] has highlighted the importance of characterizing novel methods for fabricating nanostructures. Ion beam sculpting [2] is a robust method for making solid state nanopores, but the processes involved in the fabrication process remain poorly understood. While many potentially relevant processes, such as surface diffusion [2], sputtering [3-4], anisotropic deformation via thermal spikes [5-6], ion-enhanced viscous flow [6-8], radiation-induced stresses [9], and combinations of the above [10] have been studied with $\mathrm{MeV}$ beams or with crystalline targets, there is little data available regarding interactions of lower-energy $\mathrm{keV}$ beams with amorphous materials such as those found widely in silicon-based technology. In particular, it is unclear how matter transport occurs over large length scales when irradiated with low-energy beams that deposit their energy within only a few nanometers of the surface.

In this paper, we discuss several previously unreported features of nanopore fabrication using $\mathrm{keV}$ ion beams and discuss their ramifications with respect to various extant models for the observed matter transport.

\section{EXPERIMENT}

Samples were fabricated from low-stress amorphous silicon nitride grown by lowpressure chemical vapor deposition (LPCVD) on a silicon substrate. The LPCVD was performed at Cornell's Nanofabrication Facility and yields silicon nitride thin films with a nominal tensile stress of $180 \mathrm{MPa}$ [11]. The stoichiometry is $\mathrm{Si}_{3.5} \mathrm{~N}_{4}$, as determined by Rutherford backscattering. Freestanding square membranes $90 \mu \mathrm{m}$ on a side and $500 \mathrm{~nm}$ thick were produced by lithographic patterning and a subsequent anisotropic etch of the underlying silicon substrate in $\mathrm{KOH}$. 
Starting holes of the desired diameter were drilled at the center of the freestanding membrane, from the substrate side, by rastering a 10-nm diameter, $50 \mathrm{keV}$ gallium ion beam produced by a FEI/Micrion 9500 focused ion beam (FIB) instrument. The resulting holes were conical in shape, opening towards the substrate side of the membrane with an apex angle of about 10 degrees, as determined by atomic force microscopy (AFM).

After fabrication, samples were stored in a nitrogen-purged dry box until used. To ensure consistency of results, samples not in the dry box for more than a day were stored in methanol or ethanol and blown dry with dry nitrogen immediately before use. Samples were sometimes transferred directly from the FIB to the sculpting chamber, in which case no cleaning procedures were employed.

Ion beam sculpting experiments that form "nanovolcanoes" and modify the size of the nanopore were run in a home-built ion sculpting apparatus described elsewhere [12]. The base pressure of the sculpting chamber was about $7 \times 10^{-10}$ torr with a cold can surrounding the sample in operation. The sculpting beam was a $3 \mathrm{keV}$ ion beam of $\mathrm{Ar}^{+}$with a spot size of $\sim 0.2$ $\mathrm{mm}$, which is significantly larger than the freestanding silicon nitride membrane upon which it impinges. The changing nanopore hole size was monitored instantaneously during the sculpting process with a channeltron single-ion detector located behind the sample (see Figure 1a for a highly schematic view).
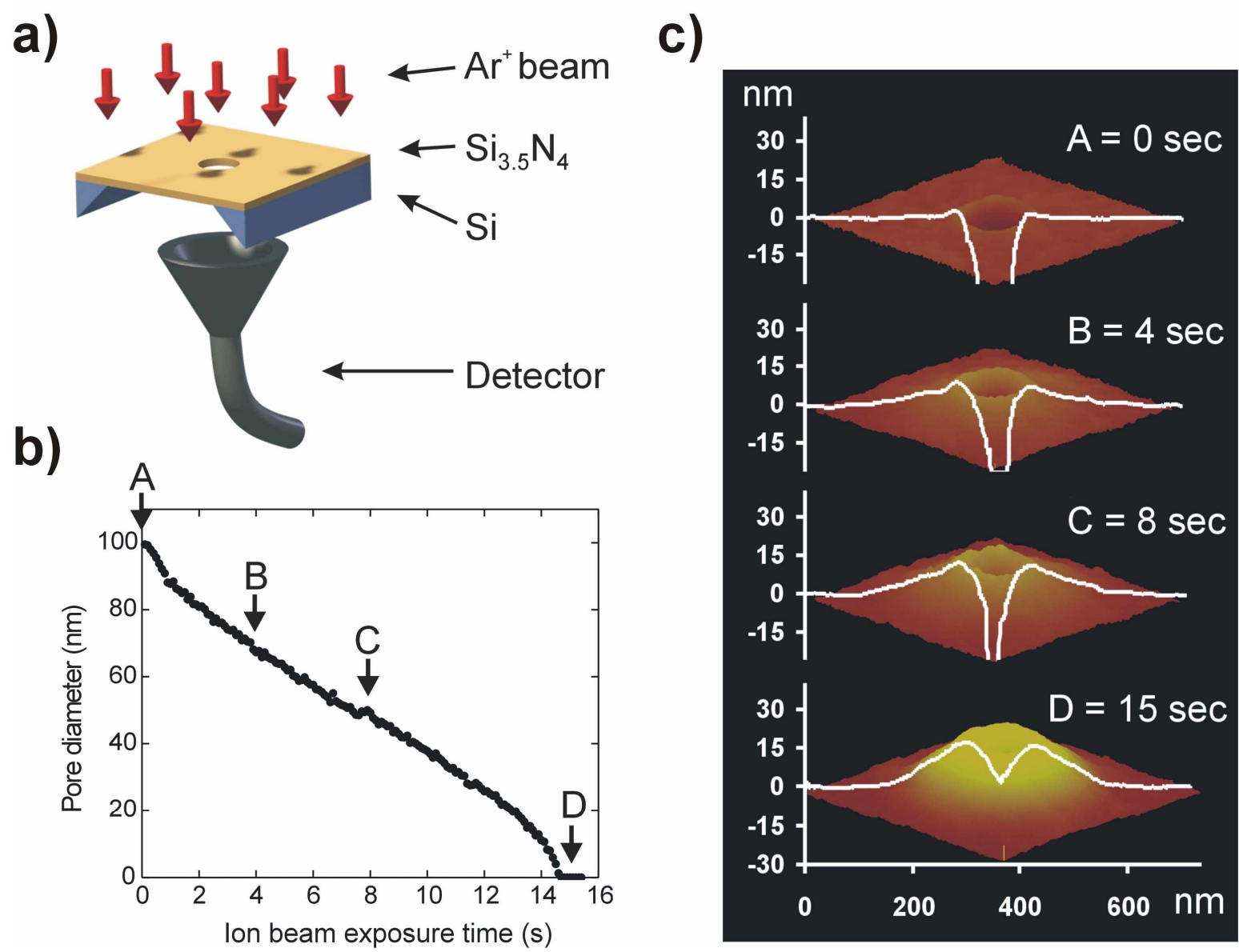

Figure 1. (a) Representation of ion sculpting experimental setup. (b) Pore shrinkage with time as deduced from the count rate. (c) Nanovolcano evolution. 
To ensure consistency of results, each sample was baked at $80{ }^{\circ} \mathrm{C}$ for 5 minutes in the sculpting chamber prior to ion beam alignment. The beam was then aligned with the pore at a temperature of $-30^{\circ} \mathrm{C}$, which is below the temperature at which most silicon nitride nanopores begin to close [2].

After ion beam sculpting the nanopores under the desired experimental conditions and recording the instantaneously changing rates at which ions were transmitted through the pore during the process, we studied the samples with an atomic force microscope. All topography analysis was performed on a Digital Instruments 3100 Nanoscope IIIa atomic force microscope (AFM) operating in tapping mode. Tips were Mikromasch NSC35A or NSC35B, with nominal tip radii of less than $10 \mathrm{~nm}$ and spring constants $7.5 \mathrm{~N} / \mathrm{m}$ and $14 \mathrm{~N} / \mathrm{m}$, respectively. Images were processed with WSxM software [13].

\section{EXPERIMENTAL RESULTS}

A typical nanopore closing curve and volcano formation observed at different stages of the pore closing process are shown in Figure $1 \mathrm{~b}$-c. This pore was sculpted at $28{ }^{\circ} \mathrm{C}$ and at a flux of $4.4 \mathrm{Ar}^{+} / \mathrm{nm}^{2} / \mathrm{sec}$. The transmitted flux through the pore is monitored by the channeltron detector (Figure 1a), producing the diameter vs. time closing curve of Figure 1b. At various stages of closing, the sample was removed from the sputtering chamber and probed with an AFM, yielding the topographs in Figure 1c [14].

\section{Temperature dependence}

We have observed that both the instantaneous closing rate (i.e. the change in nanopore area with fluence or time, or the slope of an area vs. fluence curve) and volcano size vary significantly with sample temperature. Figure 2 depicts volcano shapes at varying temperature. All pores were closed from the same initial diameter $(\sim 100 \mathrm{~nm})$ to the same final diameter $(\sim 8 \mathrm{~nm})$.

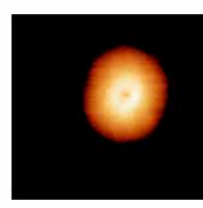

60

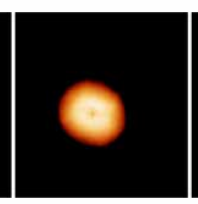

50

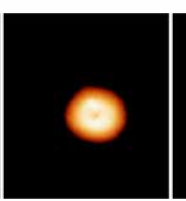

40

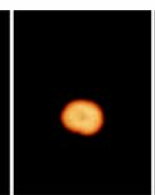

30

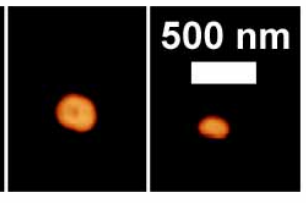

20

10
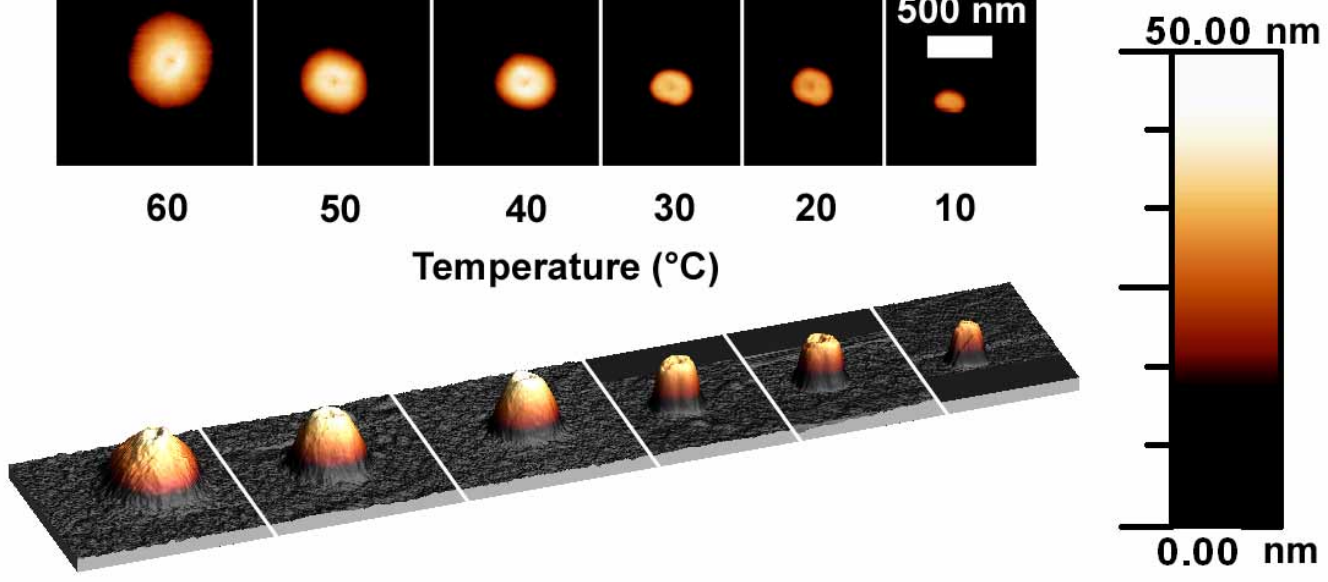

Figure 2. Nanovolcano sizes vary with temperature. Initial diameter is $100 \mathrm{~nm}$ for all pores, final diameter $8 \mathrm{~nm}$. 
It has previously been observed that pores that have been partially closed at high temperature will open at low temperature and continue closing at high temperature again [2]. Thus, a pore can be kept at approximately constant size by alternating temperatures at which the pore will open and close. Accordingly, to determine the temperature dependence of the instantaneous closing rate, the temperature of a single sample was cycled during closing. The pore was closed at $80{ }^{\circ} \mathrm{C}$ to about half its initial area. The temperature was then varied, alternating high (closing) and low (opening) temperatures to maintain a relatively constant area, as shown in Figure 3.

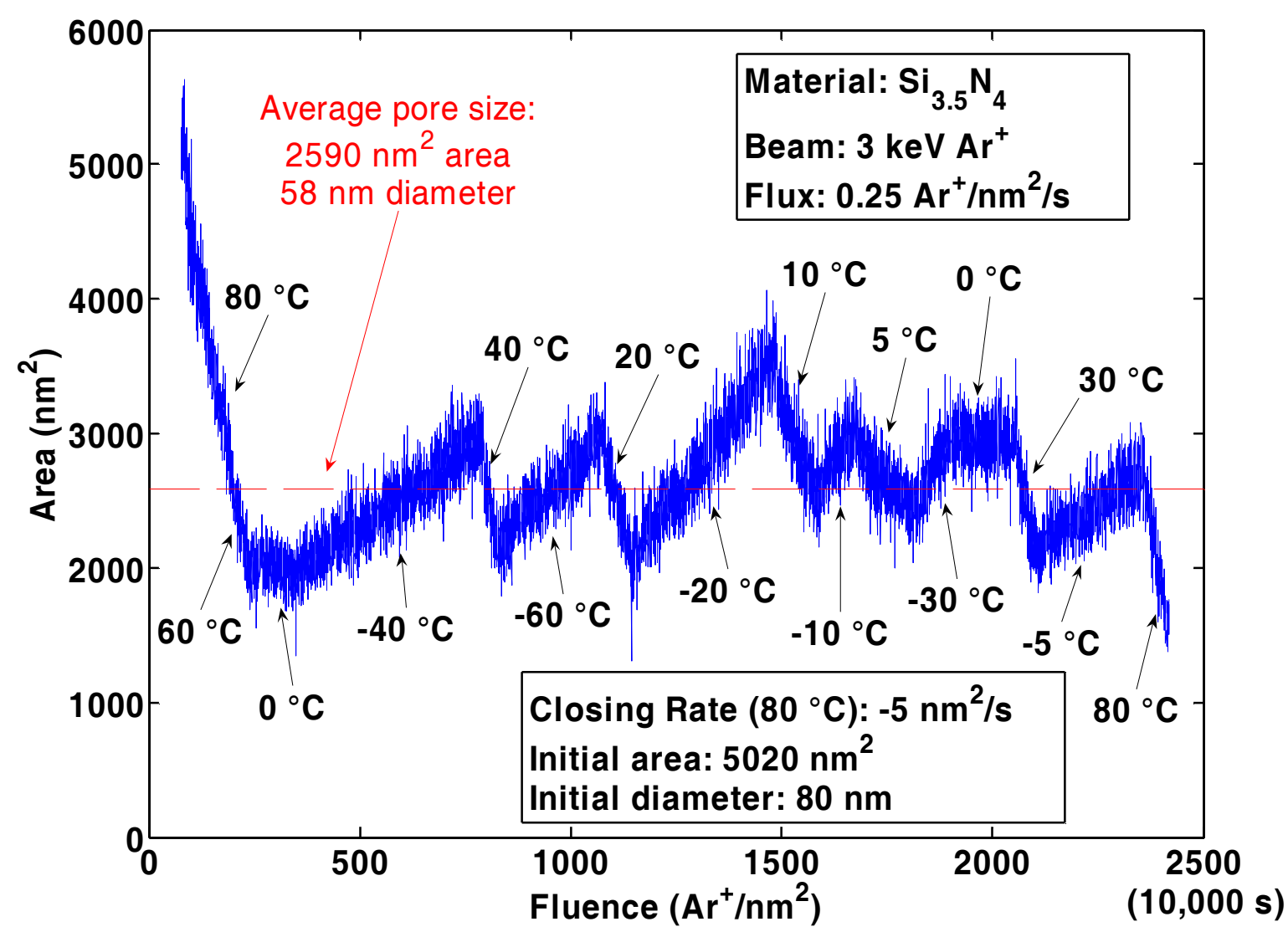

Figure 3. Nanopore ion sculpting signals vs. temperature. The red dashed line indicates the average pore size at which the closing rates in Figure 4 were calculated.

Figure 4 depicts the change in instantaneous slope with temperature, normalized to the closing rate of the pore at $80{ }^{\circ} \mathrm{C}$. The saturation of closing rate at high temperature was first observed very recently by H. B. George and M. J. Aziz in silicon oxide and amorphous silicon nanopores [15], and our data show that the same effect occurs in silicon nitride. The temperature transition seems to indicate the presence of some thermally activated process, but it is not immediately clear why that process should saturate at high temperature. We present an explanation for the saturation behavior later in this paper. 


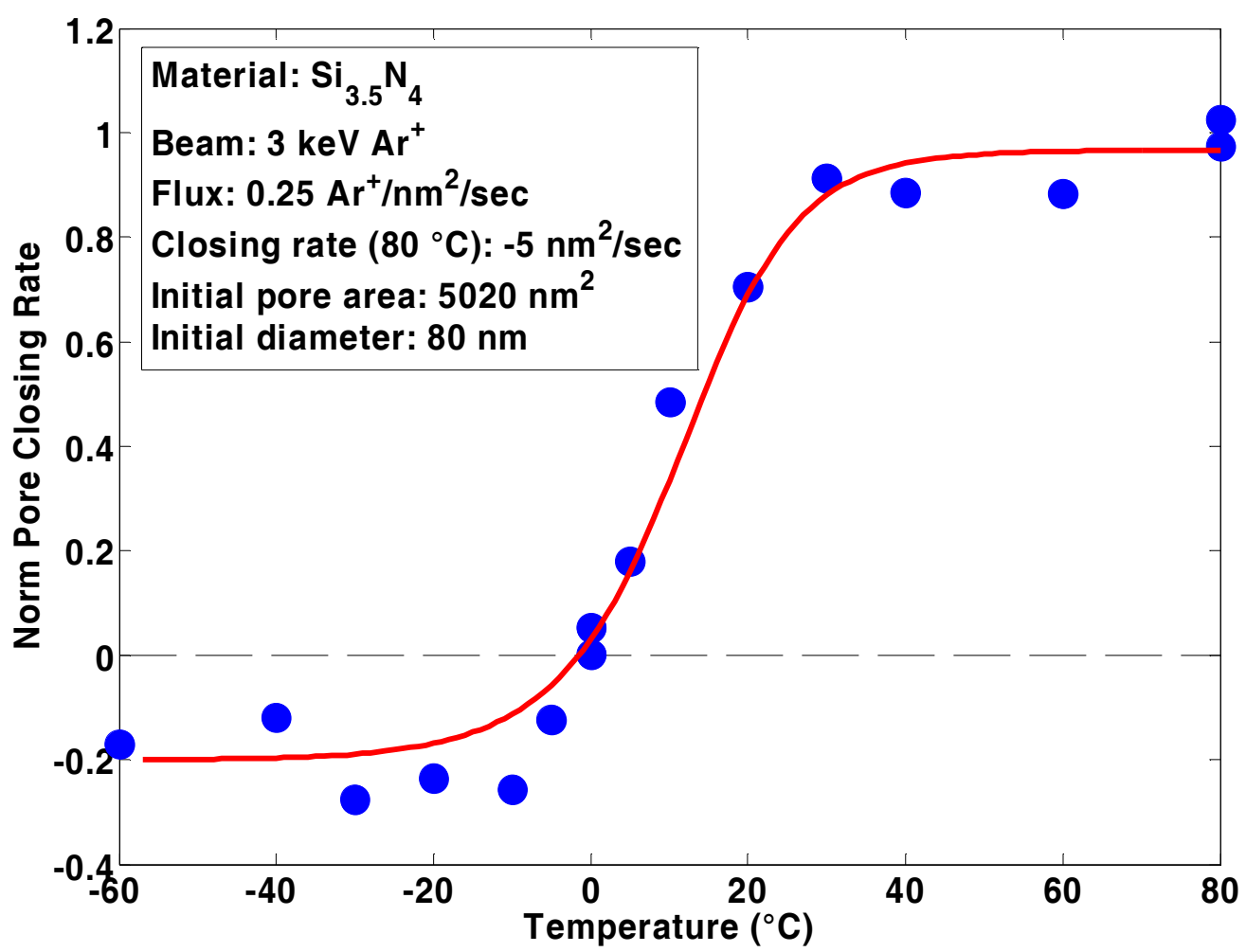

Figure 4. Nanopore ion sculpting rates vary with temperature. Rates are normalized to the area closing rate of the sample at $2590 \mathrm{~nm}^{2}$ and $80{ }^{\circ} \mathrm{C}$; negative rates indicate pore opening. The red curve is a fit to the diffusion model (discussed below).

The sensitivity of volcano size to changes in temperature in the transition region allows us to control the shape of the nanopore. Figure 5 shows three nanopores: one was closed at constant temperature, creating a standard nanovolcano; one at two different temperatures, producing a small volcano on top of a large one; and one at gradually decreasing temperatures, yielding a volcano with a smooth transition to the flat surface.

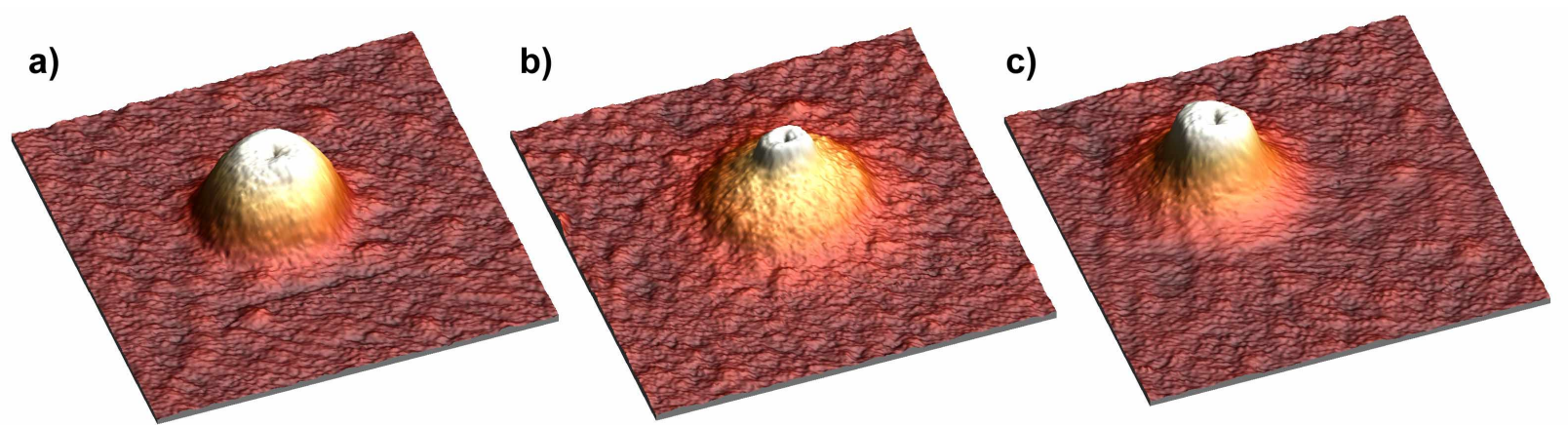

Figure 5. Ion sculpting of nanopores. Nanopores were closed at $0.9 \mathrm{Ar}^{+} / \mathrm{nm}^{2} / \mathrm{sec}$ flux, $100 \mathrm{~nm}$ initial diameter, and temperature (a) constant $40{ }^{\circ} \mathrm{C}$; (b) $60{ }^{\circ} \mathrm{C}$ to half initial area, then $20^{\circ} \mathrm{C}$; (c) temperature decreasing from $60{ }^{\circ} \mathrm{C}$ to $40{ }^{\circ} \mathrm{C}$ to $20^{\circ} \mathrm{C}$. Note the "volcano on a volcano" feature in (b). Heights are (a) $32 \mathrm{~nm}$; (b) $28 \mathrm{~nm}$; (c) $29 \mathrm{~nm}$ above the sputtered surface. All figures have lateral dimensions $1425 \mathrm{~nm} \times 1425 \mathrm{~nm}$. 


\section{$\underline{\text { Initial size dependence }}$}

We also investigated the dependence of volcano shape and size on initial pore area. Four nanopores, of nominal initial diameters $100 \mathrm{~nm}, 200 \mathrm{~nm}, 400 \mathrm{~nm}$, and $600 \mathrm{~nm}$, were closed completely under identical conditions: temperature $80^{\circ} \mathrm{C}$, flux $0.25 \mathrm{Ar}^{+} / \mathrm{nm}^{2} / \mathrm{sec}$. The membrane thickness for these pores was $250 \mathrm{~nm}$.

Pores with larger initial diameters form much larger volcanoes (see Figure 6) and thus require more material to shrink the pore by adding another "layer" to the volcano. Assuming mass transport occurs at a constant speed, pores with larger volcanoes should close more slowly at a given area, in this case $4000 \mathrm{~nm}^{2}$. Therefore, we expect that for a given instantaneous pore diameter, the closing rate should be slower for pores that started larger. Indeed, we observe that pores with initial diameters larger than $200 \mathrm{~nm}$ close more slowly with increasing pore size (see Figure 7 and Figure 8). We do not have an explanation for the drop in closing speed for small initial diameters. In order to solidify the relationship between instantaneous volcano shape and closing rate, future work might include investigating closing at some final diameter and comparing the closing rates at that diameter to the volcano shape at that point.

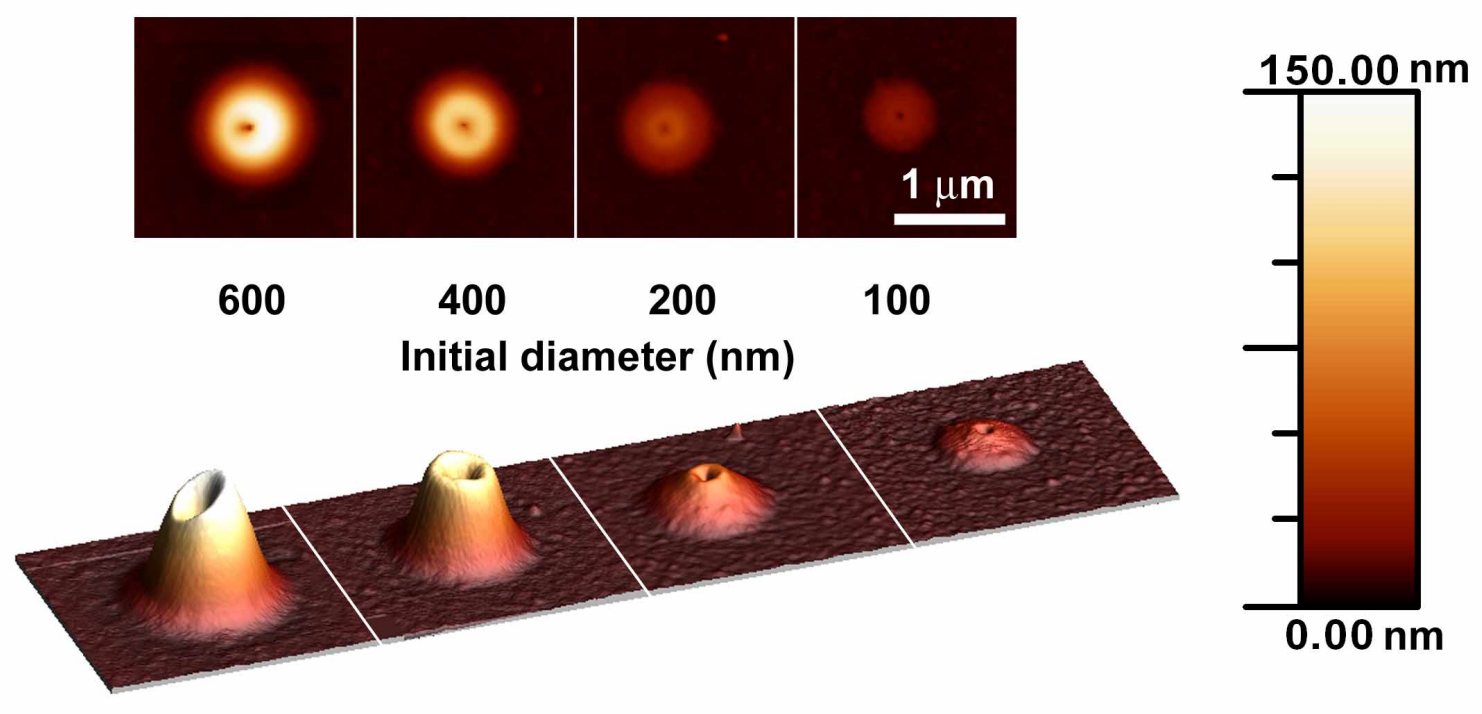

Figure 6. Initial area dependence of volcano size. All pores were closed at $80^{\circ} \mathrm{C}$ and a flux of $0.25 \mathrm{Ar}^{+} / \mathrm{nm}^{2} / \mathrm{sec}$. Initial diameters are nominal. 


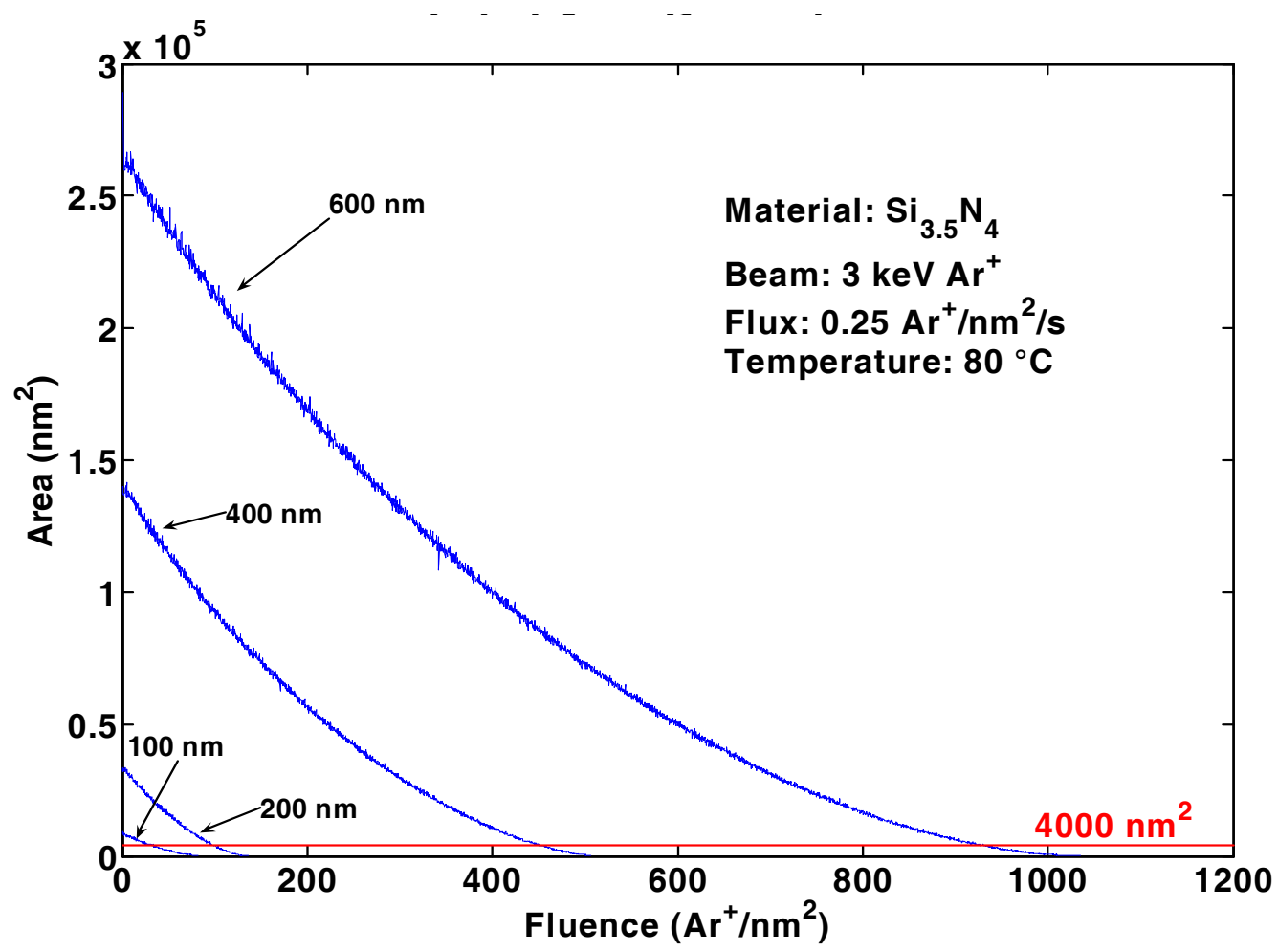

Figure 7. Dependence of ion sculpting behavior on initial nanopore area. Instantaneous slopes are compared at $4000 \mathrm{~nm}^{2}$ in Figure 8.

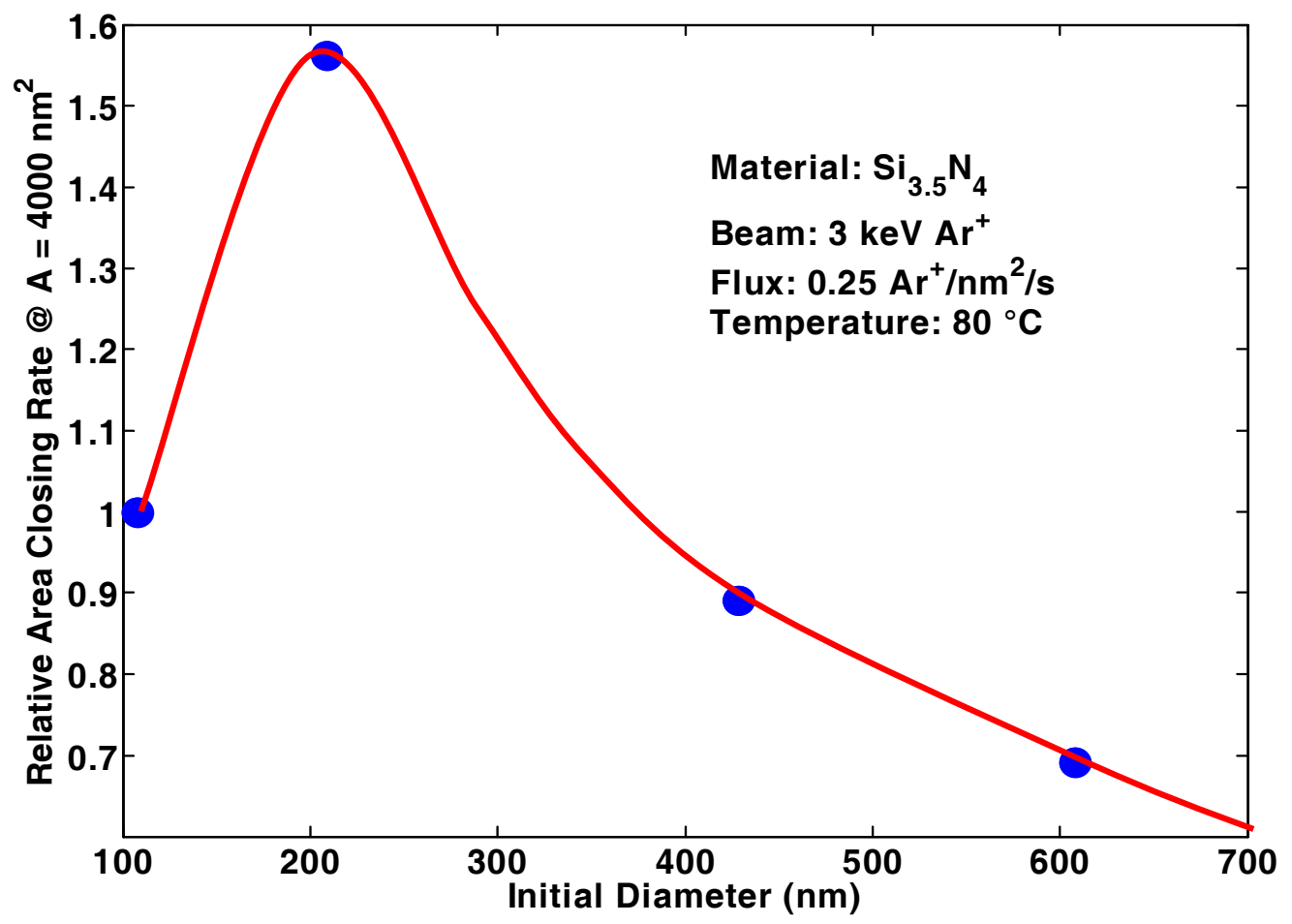

Figure 8. The closing rate at a given area relates to the initial size of the nanopore. The red curve is a guide to the eye. Initial diameters were determined by transmission electron microscopy (TEM). 


\section{DISCUSSION}

In order to explain pore closing data, various models have been explored. Originally, $\mathrm{Li}$ et. al. [2] advanced a surface diffusion model in which beam-generated adatoms diffused on the surface until they were captured by surface traps, were immobilized on the pore rim, or were annihilated by the beam. The closing behavior in this model is characterized by the parameter $X_{m}$, the average distance an adatom travels before it is trapped or destroyed by the beam, or, equivalently, the size of a depletion region of adatoms around the pore. $X_{m}$ is given by Equation 1 , where $l_{\text {trap }}$ is the average distance between surface traps, $D$ is the surface diffusivity, $\sigma$ is the cross-section for annihilation by the beam, and $f$ is the beam flux.

$\frac{1}{X_{m}{ }^{2}}=\frac{1}{l_{\text {trap }}{ }^{2}}+\frac{\sigma}{D} f$

The surface diffusion model required modification in order to explain both the accretion of relatively vast amounts of material in the nanovolcanoes and the large distances from which this material appeared to be coming. Mitsui et. al. [14], after studying sculpting dynamics of arrays of nanopores, proposed an enhancement to the diffusion process resulting from large electric fields on the surface.

The surface diffusion model also lends itself readily to incorporation of temperature effects. Except for very large pores, the closing rate is proportional to $X_{m}$. It is then clear from Equation 1 that an Arrhenius form of the surface diffusivity will yield the sigmoidal behavior observed for the temperature dependence in Figure 4. At high temperatures, where diffusion is significant, the average "lifetime" of an adatom is limited by the trap concentration $l_{\text {trap }}$. At low temperatures, the adatom is diffusion-limited and is more likely to be annihilated by the beam than to fall into a trap or reach the pore periphery. If at reduced temperatures diffusion is thermally suppressed sufficiently, the removal of material from the pore periphery by sputtering dominates, and the pore opens. A typical value for the average trap separation distance is $l_{\text {trap }} \sim$ $65 \mathrm{~nm}$. The data are not sufficiently precise to extract reliable Arrhenius parameters; we only report that the surface diffusivity varies from about 1 to $10^{3} \mathrm{~nm}^{2} / \mathrm{s}$ over the temperature range of the experiment.

The primary weakness of the surface diffusion model lies in explaining the size and shape of the volcanoes; even the possible enhancement by charging seems inadequate to explain this extraordinary effect in detail. These concerns with the diffusion model have led some to speculate about the contribution of ion-enhanced viscous flow such as that seen for $\mathrm{MeV}$ beams [6-8]. In this case the viscosity of the irradiated surface is reduced considerably by the deposition of energy from the beam, causing flow that responds to intrinsic or ion-induced stresses in the surface. It is natural to explain volcanoes as buckling due to stress relief or the result of a collective flow toward the pore. The dependence on initial pore size in this scenario may arise from differences in stress from the initial FIB milling or from the curvature of the pore.

The viscous flow model is difficult to quantify, however, and it is unclear how the observed temperature dependence would arise in such a model, where the important terms are not strongly temperature-dependent at room temperature [10]. The "thermal spike" usually 
associated with ion impingement at high energy should not be sensitive to the relatively small changes in surface temperature in our experiments.

\section{CONCLUSIONS}

Despite the new data presented in this paper, it is still inconclusive whether surface diffusion, viscous flow, a combination of these, or some other mechanism is responsible for the large matter transport observed in the ion sculpting process. We have introduced constraints on possible models based on temperature and initial size dependence and have demonstrated how these effects can be used to control the shape of a nanovolcano. Understanding the material transport mechanism and its interplay with electric fields and the underlying material properties could greatly aid in the precise fabrication of novel nanostructures.

Ion sculpting of nanopores also presents a powerful platform for studying the effects of $\mathrm{keV}$ ion beams on amorphous surfaces. Despite increasing interest in nanofabrication using labscale ion beams, a clear microscopic understanding of the interaction of $\mathrm{keV}$ ion beams with amorphous surfaces remains elusive. It is difficult to imagine modeling these interactions without elucidating and accounting for the mechanisms that create nanovolcanoes. Any answer to the question of matter transport under ion irradiation, be it individual adatom diffusion, collective flow, or a combination of the two, further influenced by implanted charge, must be able to explain the dramatic presence and morphology of nanovolcanoes.

\section{ACKNOWLEDGMENTS}

We wish to acknowledge technical and design assistance from Marc Gershow and valuable discussions with Dr. Bola George and Professor Mike Aziz. D. Hoogerheide is supported by an NDSEG graduate fellowship.

\section{REFERENCES}

1. J. Li, M. Gershow, D. Stein, E. Brandin, and J. A. Golovchenko, Nat. Mater. 2, 611 (2003).

2. J. Li, D. Stein, C. McMullan, D. Branton, M. J. Aziz, and J. A. Golovchenko, Nature (London) 412, 166 (2001).

3. H. Gnaser, Ion Irradiation of Solid Surfaces (Springer, Berlin, 1999).

4. M. A. Makeev and A.-L. Barabási, Appl. Phys. Lett. 71, 2800 (1997).

5. M. L. Brongersma, E. Snoeks, T. van Dillen, and A. Polman, J. Appl. Phys. 88, 59 (2000).

6. E. Snoeks, T. Weber, A. Cacciato, and A. Polman, J. Appl. Phys. 78, 4723 (1995).

7. H. Trinkhaus and A. I. Ryazanov, Phys. Rev. Lett. 74, 5072 (1995).

8. C. C. Umbach, R. L. Headrick, and K.-C. Chang, Phys. Rev. Lett. 87, 246104 (2001).

9. Y.-R. Kim, P. Chen, M. J. Aziz, D. Branton, and J. J. Vlassak, J. Appl. Phys. 100, 104332 (2006).

10. K. Otani, X. Chen, J. W. Hutchinson, J. F. Chervinsky, and M. J. Aziz, J. Appl. Phys. 100, 023535 (2006).

11. "CNF - Chemical Vapor Deposition Capabilities"

(http://www.cnf.cornell.edu/cnf_process_tf_cvd.html).

12. D. M. Stein, C. J. McMullan, J. Li, and J. A. Golovchenko, Rev. Sci. Instrum. 75, 900 (2004). 
13. I. Horcas, R. Fernandez, J. M. Gomez-Rodriguez, J. Colchero, J. Gomez-Herrero, and A.M. Baro, Rev. Sci. Instrum. 78, 013705 (2007).

14. T. Mitsui, D. Stein, Y.-R. Kim, D. Hoogerheide, and J. A. Golovchenko, Phys. Rev. Lett. 96, 036102 (2006).

15. H. B. George, Ph. D. thesis, Harvard University, 2007.

At the date this paper was written, URLs or links referenced herein were deemed to be useful supplementary material to this paper. Neither the author nor the Materials Research Society warrants or assumes liability for the content or availability of URLs referenced in this paper. 